\title{
DC utilization of existing LVAC distribution cables
}

DOI:

10.1109/EIC.2013.6554302

Link to publication record in Manchester Research Explorer

\section{Citation for published version (APA):}

Antoniou, D., Tzimas, A., \& Rowland, S. M. (2013). DC utilization of existing LVAC distribution cables. In 2013 IEEE Electrical Insulation Conference, EIC 2013/IEEE Electr. Insul. Conf., EIC (pp. 518-522)

https://doi.org/10.1109/EIC.2013.6554302

\section{Published in:}

2013 IEEE Electrical Insulation Conference, EIC 2013|IEEE Electr. Insul. Conf., EIC

\section{Citing this paper}

Please note that where the full-text provided on Manchester Research Explorer is the Author Accepted Manuscript or Proof version this may differ from the final Published version. If citing, it is advised that you check and use the publisher's definitive version.

\section{General rights}

Copyright and moral rights for the publications made accessible in the Research Explorer are retained by the authors and/or other copyright owners and it is a condition of accessing publications that users recognise and abide by the legal requirements associated with these rights.

\section{Takedown policy}

If you believe that this document breaches copyright please refer to the University of Manchester's Takedown Procedures [http://man.ac.uk/04Y6Bo] or contact uml.scholarlycommunications@manchester.ac.uk providing relevant details, so we can investigate your claim.

\section{OPEN ACCESS}


This is the accepted manuscript, which has been accepted by IEEE for publication.

(C) 2013 IEEE. Personal use of this material is permitted. Permission from IEEE must be obtained for all other uses, in any current or future media, including reprinting/republishing this material for advertising or promotional purposes, creating new collective works, for resale or redistribution to servers or lists, or reuse of any copyrighted component of this work in other works. The full reference is:

\section{'DC utilization of existing LVAC distribution cables'}

D. Antoniou, A. Tzimas, and S. M. Rowland

IEEE Electrical Insulation Conference (EIC) 2013 , Page(s): 518 - 522

Digital Object Identifier: 10.1109/EIC.2013.6554302 


\title{
DC Utilization of Existing LVAC Distribution Cables
}

\author{
D. Antoniou, A. Tzimas and S. M. Rowland \\ The University of Manchester \\ School of Electrical and Electronic Engineering \\ M13 9PL, UK
}

\begin{abstract}
Low Voltage (LV) AC cables are predominant in distribution networks across the world. The possibility of transforming such networks to DC may hold significant advantages and it is widely being considered. In particular it may allow a greater flow of electrical energy within urban areas, allowing adoption of electrical vehicles and Smart Grid applications. Distribution networks in UK use well established 4core Paper Insulated Lead Covered (PILC) belted cables as well as newer cross linked polyethylene (XLPE) screened cables. Optimal utilization of existing conductors in the cables is of paramount importance in order to fully take advantage of the infrastructure. DC can be applied using a unipolar or a bipolar configuration. Both configurations possess advantages in different situations therefore both are considered in this study. This paper investigates different scenarios and proposes the optimal configurations for an LVDC distribution network. The implications for optimizing power flow are considered.
\end{abstract}

\section{INTRODUCTION}

This work is part of the Top and Tail Project, a collaborative blue-sky project funded by the EPSRC Grand Challenge Programme [1]. The project is focused on the physical infrastructure change in energy networks required to move the UK to a low carbon economy thereby contributing to the UK Governments' target of reducing $\mathrm{CO}_{2}$ emissions by 2050. The project is divided in to two parts, the 'Top' and the 'Tail'. The former focuses on the Transmission part of the network whereas the latter focuses on the last mile of the Distribution Network. This work reported here is part of the 'Tail'.

The move of the electrical distribution network from the legacy LVAC (Low voltage Alternating Current) system to LVDC (Low voltage Direct Current) poses significant benefits and its practicability is being analysed in this study. Several studies have proposed that the change from LVAC to LVDC can substantially increase the power capacity of the system as well as minimise the losses in the system [2]. Electricity demand is rising and will continue to increase in the following years due to the increased amount of electrical space heating and introduction of electric vehicles (EVs). A viable solution to the problem is needed to allow the distribution system to cope.

Operating an existing LVAC cable under DC gives a theoretical maximum power capacity of $\sqrt{ } 2$ times that of an AC system. This is due to AC systems being operated at RMS (Root Mean Square) voltage whereas under DC they could potentially run at the AC peak voltage. This assumes that the reliability of a cable under $\mathrm{AC}$ is the same as that under DC running at peak voltage. DC also benefits from the lack of skin and proximity effects, and no dielectric losses, leading to lower losses in the system.

Ofgem statistics show that DNOs (Distribution Network Operators) have an annual loss percentage of 5.8\% [3]. This translates to $18777 \mathrm{GWh}$ (Giga Watt hours) of energy being lost in the UK distribution network each year. The UK distribution network consisted of around $457,965 \mathrm{~km}$ of underground cables in the year 2000 [4]. Data from the past ten years shows no major reductions in the system losses in that time. These energy losses translate to higher $\mathrm{kWh}$ price for the end consumer. A breakdown of electricity prices shows that distribution and supply together account for a $53.5 \%$ of the total cost of electricity.

If DC is to be used in the network, the replacement of these urban buried cables does not seem to be the best option either economically or practically. The feasibility of using existing cable infrastructure is discussed in the following sections.

\section{THE DISTRIBUTION NETWORK}

The UK distribution network mainly consists of three operating voltages: $33 \mathrm{kV}, 11 \mathrm{kV}$ and $400 \mathrm{~V}$ phase-to-phase. These voltages are operated on both overhead lines and underground cables. This paper considers only the $400 \mathrm{~V}$ part of the network that operates on underground buried cables.

In the UK there are three types of system connections between the supply distribution transformer and the consumer. These are the TT (terra terra), TN-S (terra neutral-separate) and TN-C-S (terra neutral-combined-separate) and are illustrated in Figure 1. In a TT system, primarily used where a connection is taken from an overhead line, the supply transformer is earthed on site and the consumer unit is earthed through an electrode buried directly into the ground. The TN-S system is the most popular system connection currently in the UK and consists of an earthed supply providing an earth connection to the end consumer unit. New systems installed the UK will employ a TN-C-S connection where the neutral of the supply is used as the neutral and earth combined [5]. Underground cables are mostly used for the TN-S and TN-C-S systems.

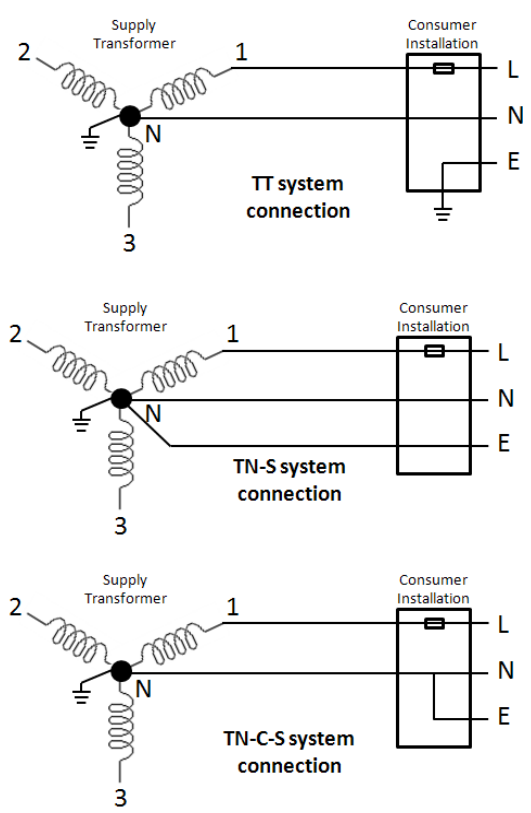

Figure 1 - System connection configurations 
The LV distribution network is a $400 \mathrm{~V}, 3$-phase system. Residential premises are usually connected with a single phase at $230 \mathrm{~V}$ phase-to-ground. When more power is required, a 3phase connection is provided. Depending on the topology, several premises are evenly distributed along a cable route as shown in Figure 2. Phase imbalances introduce an increase in return currents, increase system losses and voltage imbalances. Careful planning is needed when connecting end nodes to each phase in order to ensure optimal system quality.

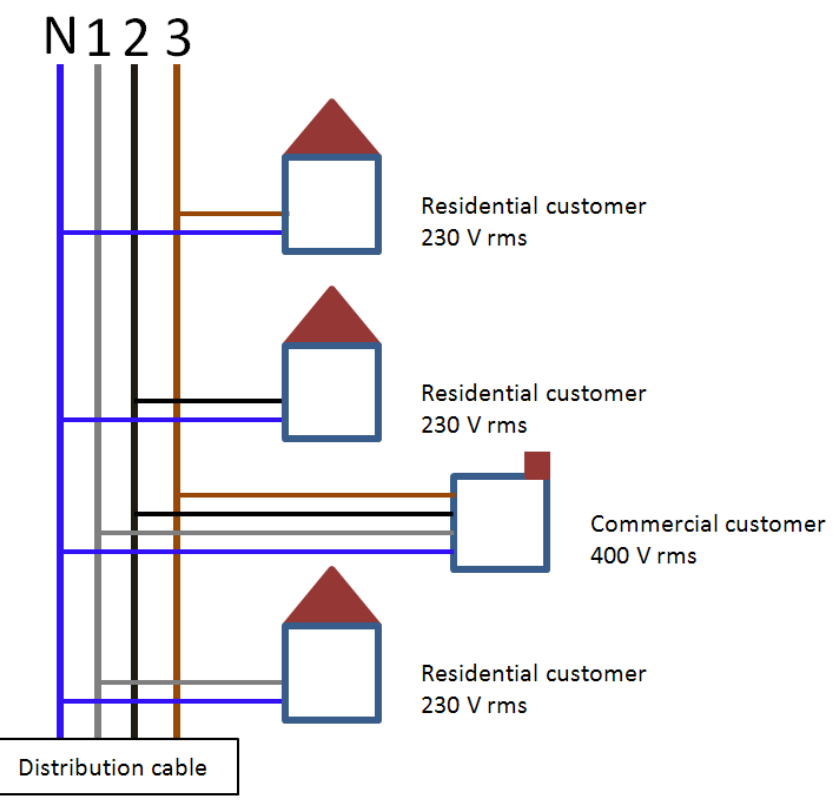

Figure 2 - Connections on a distribution cable

The system runs under AC voltage thus all the voltages mentioned above are RMS voltages and each phase in the LV network peaks at $325 \mathrm{~V}$ to ground. When a phase-to-phase measurement is taken, the maximum voltage potential observed is $325^{*} \sqrt{ } 3=563 \mathrm{~V}$. An increase in power transfer through these cables can only be achieved by increasing the system voltages since the current is limited by the thermal ratings of the cables [6]. TN-S systems usually use a PILC (Paper insulated lead covered) 4-core belted cable and TN-C-S systems use 3-core XLPE cables. However many variations in design are used and are present in any network. The characteristics of these cables are further discussed in the next section.

The types of cables used in any given network might be known but it is very difficult to know all the topologies employed across the whole of the UK. Extensions to the network and new connections are carried out all the time. This increases the complexity in deciding if the network can be operated under DC.

\section{EXISTING CABLES}

The most common cable used in the UK LV distribution network before the 1970s was the BS6480 PILC 4-core belted cable [7]. The cable is rated at $600 / 1000 \mathrm{~V}$ (phase to ground/ phase to phase). The arrangement of the cable is shown in
Figure 3. This cable consists of four copper conductors, three for the live phases and one for neutral. Paper insulation is applied to all conductors and in the case of a belted cable design; an extra layer of insulation exists around all conductors. The next layer is a lead sheath which is usually grounded. Covering the lead sheath there is a layer of either a steel wire or tape armour used to provide stiffness to the cable and protection. The last layer of the cable is the oversheath (jacket) which is usually made of PVC or bitumen. This type of cable is most notably found in a TN-S system. The neutral is separated from the earth which usually is connected to the sheath and armour wires.

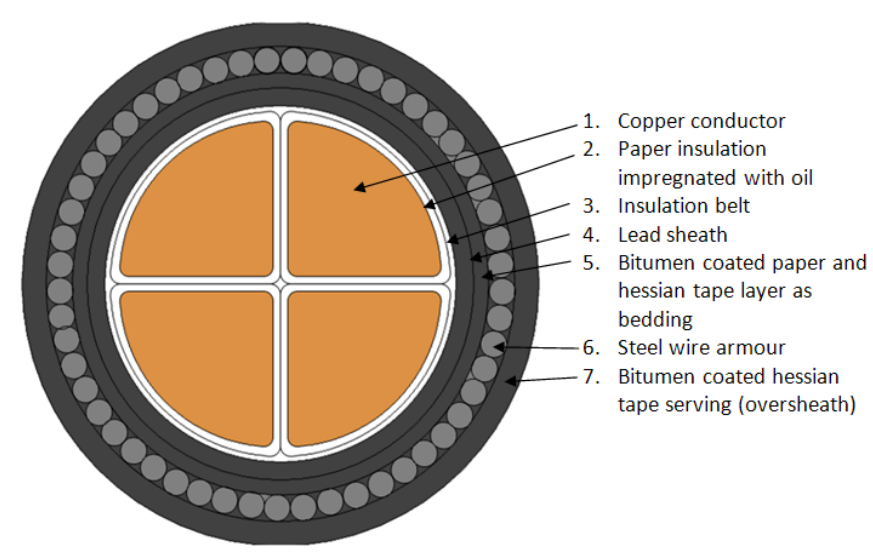

Figure 3 - 4-core PILC cable

Since the 1970s, XLPE insulated cables have generally been used in any extensions or new circuits. These can either be 3core or 4-core. The 4-core cables are used only for repairing or replacing old PILC cables already in service. The most common 3-core XLPE cable used in the UK is the BS7870 cable [8]. This cable consists of three solid aluminium or copper conductors to carry the three phases. Each conductor is insulated with XLPE. The next layer is rubber bedding for the combined neutral/earth copper wires that are shaped to assist jointing and give the cable greater physical flexibility. The final layer is a PVC sheath. These cables are mainly used in a TN-C-S system since the neutral and earth connections are combined therefore there is no need for a separate neutral conductor as in a TN-S system.

\section{Potential BENEFITS OF DC}

Power in an AC system is normally considered to consist of both real and imaginary parts. The Complex power (S) then consists of imaginary Reactive power (Q) and real or active power $(\mathrm{P})$, the vector sum of the two being the Apparent power $(|\mathrm{S}|)$. In a DC system the power is simply the product of the magnitude of the current and voltage. In the AC case, reactive power does not transfer any useful energy and increases circulating currents in the network thus increasing losses and reduce the efficiency of the system. Operating the network under DC will eliminate this problem. 
Cables in the AC network operate at $325 \mathrm{~V}$ peak. As a result it might be assumed that the cables can be run at $325 \mathrm{Vdc}$. This clearly represents an increase in the total power capacity of the cable. Furthermore, these cables are rated at 600/1000 V (phase to ground/ phase to phase) considerably higher than the present operating voltage. Running these cables at their rated voltage can further increase the power capacity of the cables. One option is to increase the AC voltage. This will obviously increase power capacity but will never exceed the power capacity achievable under DC due to the peak voltage advantage discussed previously. Increasing the AC voltage furthermore increases absolute losses. Such losses translate to heat generation which also age the cables faster.

Operating the existing cables under DC eliminates the need of digging up cables and replacing them with new ones. This saves both time and financial investment. One issue of this is the unknown ageing state of the cables in the ground. Raising the voltage might age the insulation faster or even cause electrical breakdowns due to the change from AC to DC. These concerns will be addressed in a separate study.

\section{UNIPOLAR/BIPOLAR CONFIGURATION}

DC is used extensively in HVDC (High Voltage Direct Current) networks. HVDC links are employed for long distances and are used to transfer power between asynchronous AC networks. The two basic DC connection configurations are unipolar and bipolar. In the unipolar case, one metallic conductor is used to carry the current while the return current uses an earth return through special electrodes buried at each side of the line. Figure 4 shows such an arrangement. The lack a return metallic conductor dramatically cuts costs but can cause electrochemical corrosion. In undersea connections the electrodes can produce chlorine which affects the seawater quality [9]. A solution to this is to use a metallic earth return to curry the return current.

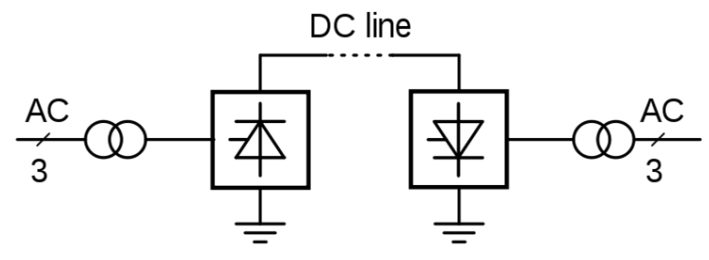

Figure 4 - Unipolar configuration

The second major configuration is the bipolar configuration. Two metallic conductors are used to carry current in opposite polarities relative to the ground. This configuration can carry more power with cables rated for lower voltages. A $\pm 500 \mathrm{kV}$ line only requires each cable to withstand $500 \mathrm{kV}$ whereas under a unipolar configuration the cable must withstand $1000 \mathrm{kV}$ for the same power capacity. A bipolar cable can also include a dedicated earth return. One advantage of the bipolar configuration that uses an earth return is that, in case of failure on one of the polarities, the system can still operate at half its capacity. One of the disadvantages of a bipolar configuration is the cost of the extra line. Figure 5 shows a typical bipolar configuration.

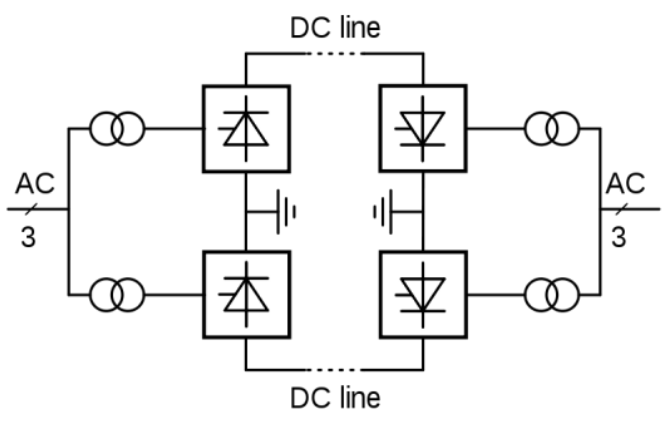

Figure 5 - Bipolar configuration

A third unproven system, patented in 2004, using a tripolar configuration aims to convert existing $\mathrm{AC}$ systems to $\mathrm{DC}$ utilising all thee conductors in the AC circuit using current modulation to spread thermal load across all conductors [10]. One of the proposed setups is to cycle the thermal load between the conductors. One conductor operates at 1.5 times the maximum thermal rating with the remaining two at 0.75 times. The high current is periodically cycled evenly spreading the thermal load across all the conductors in the circuit. This allows the full utilisation of all three conductors and can supply more power in case of a fault in one of the conductors. A disadvantage of this configuration is the frequent field reversal which might facilitate insulation ageing. No tripole configuration is in operation yet. This configuration might prove useful for HVDC, but the cost of implementation in the LV distribution network is likely to prove to too high.

\section{OPTIMAL CONFIGURATIONS}

The two cables (four- and three-core) present in the UK distribution network mentioned previously come in various conductor sizes. Depending on the power demand, different sized cables are used in different parts of the network. In this study, to simplify the process, both types of cables are chosen to have a current rating of $265 \mathrm{~A}$ per core. This value is derived from tables in the cable standards [7,8]. Under AC the maximum power through both cables is $183 \mathrm{~kW}$. This assumes a unity power factor. In reality there will be a power factor decreasing the useful power delivered.

DC should at least match or exceed the power capacity of the cable under AC in order for it to have some potential value. The polymeric cable has three cores compared to four in the paper insulated cable. This places the polymeric cable in a disadvantaged position when considering an optimal power capacity under DC. In Table 1, different configurations are considered for the 3-core cable utilising DC in unipolar and bipolar configurations. In order to reach the AC total power using DC in unipolar configuration, the voltage should be raised to $690 \mathrm{Vdc}$. This might seem high but these cables are rated at $600 \mathrm{Vrms}$ therefore theoretically they should withstand voltages up to $849 \mathrm{~V}(=600 * \sqrt{2})$. Operating the cable under that voltage will yield a power of $225 \mathrm{~kW}$. One of the cores will not be in use in such a configuration. Using DC bipolar, the AC total power is reached when operating two of the conductors at $\pm 344 \mathrm{~V}$. This voltage is very close to the peak value of 
230 Vrms. Under the bipolar configuration, the $845 \mathrm{~V}$ voltage per conductor cannot be used because the cable can only withstand 1000 Vrms (1414 Vdc) phase to phase.

The maximum total power under this configuration is $375 \mathrm{~kW}$. Comparing this value with the potential maximum power that can be obtained running the cores at 600 Vrms AC, suggests that in a 3-core cable, DC might not be such a good alternative. Figure 6 shows how these configurations apply to the 3-core cable.

Running the 4-core PILC cable under DC can significantly increase the cable capacity compared to AC. Table 2 compares the different configurations in both unipolar and bipolar configurations. Under the unipolar configuration at $344 \mathrm{~V}$ the total power is matched to that of the cable running under AC. Under bipolar configuration, even at $230 \mathrm{Vdc}$ the total power exceeds that of the AC case. It is clear that the bipolar configuration poses significant advantages in the 4-core cable. Power capacity in DC is several times larger compared to AC depending on the voltage level, see Table 2.

The tripolar configuration might be difficult to implement in the distribution network since there will be a need to modulate current and as a result alternate the voltage levels on each conductor. Applying this configuration between two substations will be less of a problem. Implementation in the distribution network will require each premise connected to the distribution cable to have a means of compensation for the varying voltage levels between the conductors. This might prove to be expensive but with technology advancements in the future the price of the components required for such arrangement might drop to acceptable levels.

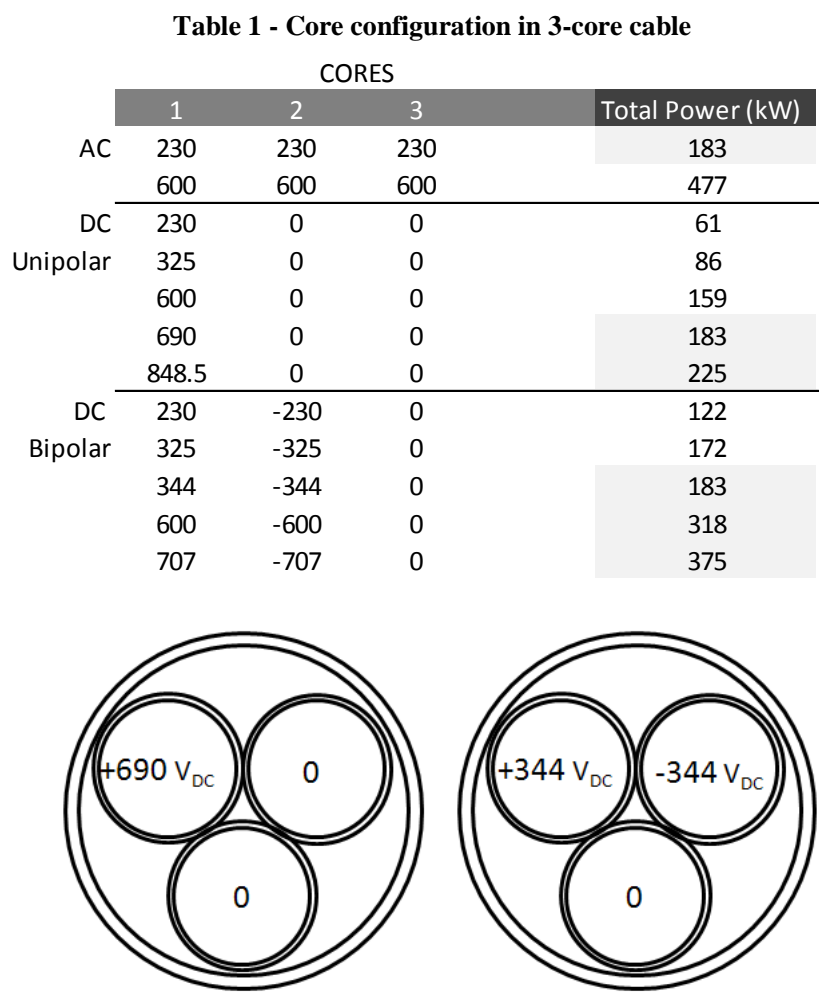

Figure 6 - 3-core cable configurations for maximum power capacity
Table 2 - Core configuration in 4-core cable

\begin{tabular}{rccccc}
\multicolumn{7}{c}{ CORES } \\
\cline { 2 - 6 } AC & 1 & 2 & 3 & 4 & Total Power $(\mathrm{kW})$ \\
\cline { 2 - 6 } DC & 230 & 230 & 230 & 0 & 183 \\
\cline { 2 - 6 } Unipolar & 600 & 600 & 600 & 0 & 477 \\
\hline & 325 & 0 & 325 & 0 & 122 \\
& 344 & 0 & 344 & 0 & 172 \\
& 600 & 0 & 600 & 0 & 183 \\
Bipolar & 325 & -325 & 325 & -325 & 318 \\
\cline { 2 - 6 } & 230 & -230 & 230 & -230 & 244 \\
& 600 & -600 & 600 & -600 & 636 \\
& 707 & -707 & 707 & -707 & 749
\end{tabular}

\section{SYSTEM RE-WIRING}

The current distribution network will require re-wiring in order to accommodate a DC system. Under AC, all the nodes in the network are connected to the neutral connection as shown in Figure 7. The currents cancel out on the return path, consequently the neutral conductor caries no current under normal operating conditions. Current only circulates in case of a fault or imbalance between the phases. This will not be the case under DC. Current circulates in both positive and negative conductors. Re-wiring will need to take place to evenly distribute the current through the conductors. Leaving the connections as they are will result in over-rated current flowing through the neutral conductor exceeding its operation levels. Figure 8 shows two possible re-wirings utilising four cores in a cable.

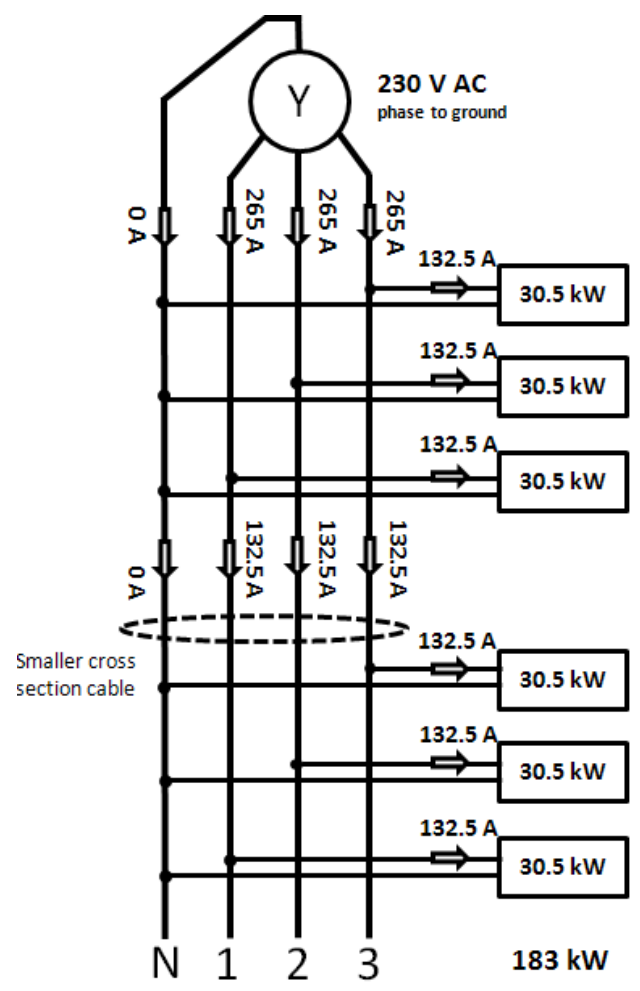

Figure 7 - System wiring under AC 

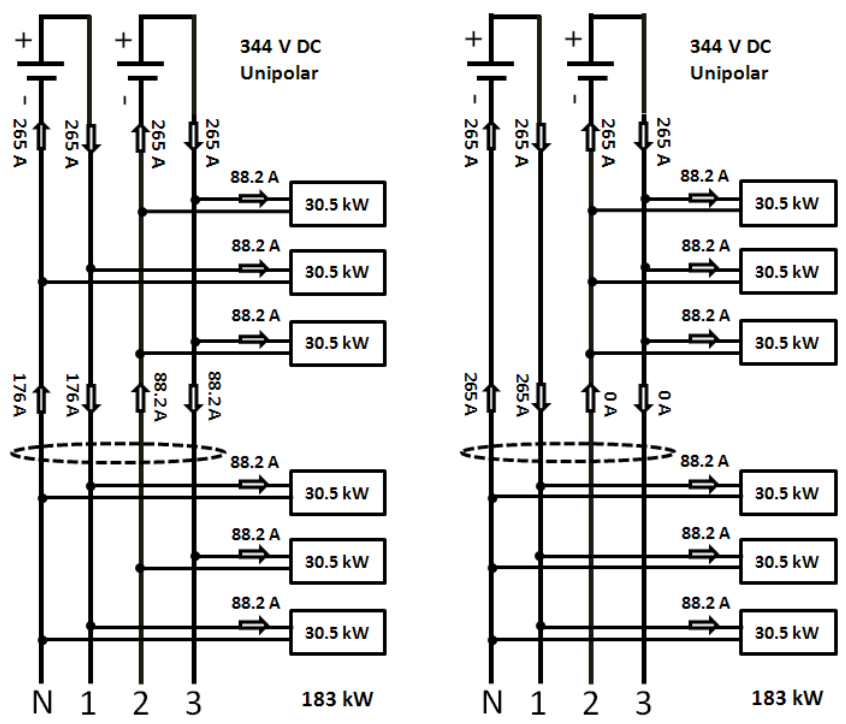

Figure 8 - System wirings under DC utilising four cores

In an $\mathrm{AC}$ distribution main line, the conductor cross sectional area can be reduced after a certain number of node connections since the current flowing through the cable reduces as shown in Figure 7. Re-wiring for use under DC might cause an increase in current flowing in those parts of the line as shown in Figure 8. In the $\mathrm{AC}$ system the current after the dashed region drops to $132.5 \mathrm{~A}$, whereas in the two DC system re-wirings, the current rises to $176 \mathrm{~A}$ and $265 \mathrm{~A}$ respectively. Figure 9 shows two system configurations under DC utilising two conductors in the cable. In these cases the current flowing is the same as in the AC case. By increasing the voltage, the same power is delivered by only two conductors. In the configurations shown in Figure 9, nodes could be connected to Conductor 1 as well in order to split the return current. Splitting the return current equally between conductor 1 and 2 can also reduce the $\mathrm{I}^{2} \mathrm{R}$ losses.
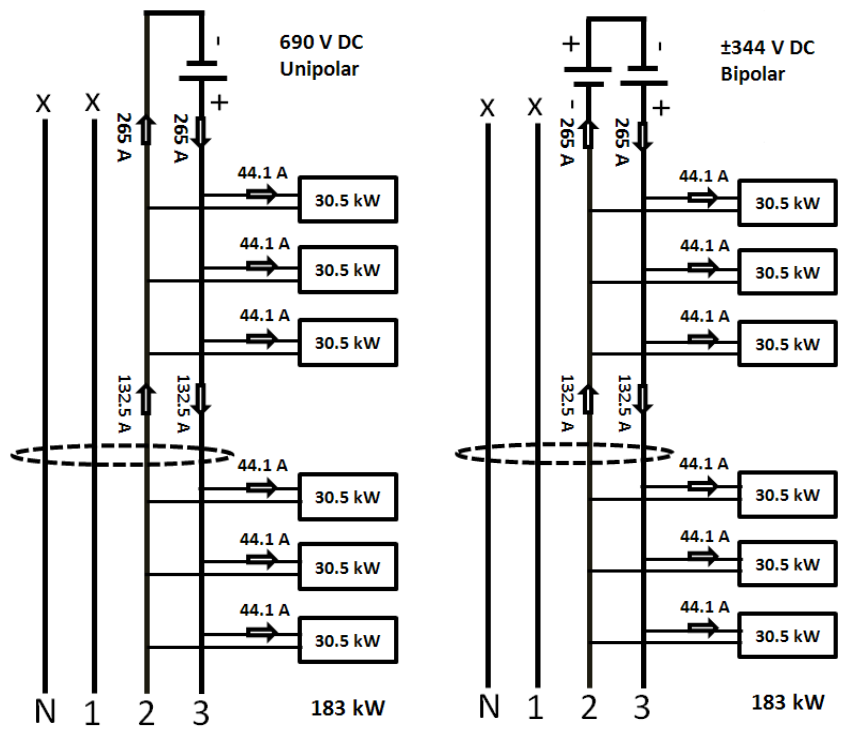

Figure 9 - System wirings under DC utilising two conductors
Utilising all four cable conductors of the 4-core PILC cable will cause incompatibilities when connecting to the newer 3core XLPE cable. The normal practice is to combine the neutral and earth connections from the 4-core cable on the combined neutral/earth connection on the 3-core cable. As a result, a maximum of three conductors can be utilised.

\section{SUMMARY AND CONCLUSIONS}

Utilising existing LVAC cables under DC may increase the total power transfer in most cases. By increasing the voltage to the maximum rated voltages dictated by the manufacturers, a clear increase in power transfer can be achieved. A major setback for this proposition is the need to rewire all the nodes connected to the network in order to optimise the current flow in the system. This might prove very expensive and time consuming. The bipolar configuration is the most optimal for higher power transfer while keeping the current levels within the rated limits. Incompatibilities might arise when the old 4core cables are joined with the newer 3-core cables. Careful rewiring planning will be necessary to avoid any system overloading. These conclusions are based on the assumptions that the cables can withstand those higher voltages. Further studies will focus on the reliability of these cables running under DC and how ageing might affect this. Ultimately this is a dielectrics reliability issue.

\section{ACKNOWLEDGMENTS}

The authors gratefully acknowledge the RCUK's Energy Programme for the financial support of this work through the Top \& Tail Transformation programme grant, EP/I031707/1 (http://www.topandtail.org.uk/).

\section{REFERENCES}

[1] www.topandtail.org.uk , [accessed 12/02/2013]

[2] Borioli, E.; Brenna, M.; Faranda, R.; Simioli, G.; , "Comparison between the electrical capabilities of the cables used in LV AC and DC power lines," Harmonics and Quality of Power, 2004. 11th International Conference on, vol., no., pp. 408- 413, 12-15 Sept. 2004

[3] Ofgem, "Distribution Units and Loss Percentages Summary", 02/08/2010

[4] Scott Butler, "The nature of UK electricity transmission and distribution networks in an intermittent renewable and embedded electricity generation future", (http://www.parliament.uk/documents/post/e5.pdf), p.37, [accessed: 12/02/2013]

[5] British Standard, "Requirements for Electrical Installations (BS7671: 2008)”, 17th edition, pp. 32-34, 2008

[6] Tzimas, A.; Antoniou, D.; Rowland, S.M.; , "Low voltage DC cable insulation challenges and opportunities," Electrical Insulation and Dielectric Phenomena (CEIDP), 2012 Annual Report Conference on, vol., no., pp. 696-699, 14-17 Oct. 2012

[7] British Standard, "Specification for impregnated paper-insulated lead or lead alloy sheathed electric cables of rated voltages up to and including 33000 V (BS6480:1988)", February 1988

[8] British Standard, "LV and MV polymeric insulated cables for use by distribution and generation utilities (BS7870:2011)", December 2011

[9] J.C. Moldurg, J.A. Kavichy, K.C.Picel, "The Design, Construction, and Operation of Long Distance High-Voltage Electricity Transmission Technologies", (http://www.solareis.anl.gov/documents/docs/ APT_61117_EVS_TM_08_4.pdf),p.45, [accessed: 12/02/2013]

[10] Barthold, Lionel $\mathrm{O}$, "Current modulation of direct current transmission lines”, United States Patent 6714427, 30/03/2004 